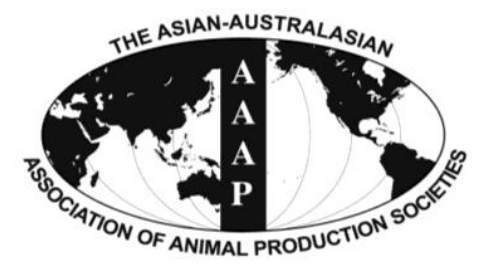

Asian-Aust. J. Anim. Sci.

Vol. 25, No. 12 : 1742-1747 December 2012

http://dx.doi.org/10.5713/ajas.2012.12352

www.ajas.info

pISSN 1011-2367 elSSN 1976-5517

\title{
Effect of Fermented Chlorella Supplementation on Growth Performance, Nutrient Digestibility, Blood Characteristics, Fecal Microbial and Fecal Noxious Gas Content in Growing Pigs
}

\author{
L. Yan, S. U. Lim ${ }^{1}$ and I. H. Kim* \\ Department of Animal Resource and Science, Dankook University, Cheonan, Choognam 330-714, Korea
}

\begin{abstract}
A total of 96 growing pigs ((Landrace $\times$ Yorkshire $) \times$ Duroc; $\mathrm{BW}=26.58 \pm 1.41 \mathrm{~kg})$ were used in a 6 -wk feeding trail to evaluate the effects of fermented chlorella (FC) supplementation on growth performance, nutrient digestibility, blood characteristics, fecal microbial and fecal noxious gas content in growing pigs. Pigs were randomly allotted into 1 of 4 dietary treatments with 6 replicate pens ( 2 barrows and 2 gilts) per treatment. Dietary treatments were: i) negative control (NC), basal diet (without antibiotics); ii) positive control (PC), $\mathrm{NC}+0.05 \%$ tylosin; iii) (fermented chlorella 01) FC01, $\mathrm{NC}+0.1 \% \mathrm{FC}$, and iv) fermented chlorella 02 (FC02), $\mathrm{NC}+0.2 \%$ FC. In this study, feeding pigs PC or FC01 diets led to a higher average daily gain (ADG) and dry matter (DM) digestibility than those fed NC diet $(p<0.05)$, whereas the inclusion of FC02 diet did not affect the ADG and DM compared with the NC group. No difference ( $p>0.05)$ was observed on the body weight, average daily feed intake (ADFI), gain:feed (G:F) ratio, the apparent total tract digestibility of $\mathrm{N}$ and energy throughout the experiment. The inclusion of PC or FC did not affect the blood characteristics ( $p>0.05$ ). Moreover, dietary FC treatment led to a higher $(\mathrm{p}<0.05)$ lactobacillus concentration and lower $E$. coli concentration than the NC treatment, whereas the antibiotic supplementation only decreased the $E$. coli concentration. Pigs fed FC or PC diet had reduced $(\mathrm{p}<0.05)$ fecal $\mathrm{NH}_{3}$ and $\mathrm{H}_{2} \mathrm{~S}$ content compared with those fed $\mathrm{NC}$ diet. In conclusion, our results indicated that the inclusion of FC01 treatment could improve the growth performance, nutrient digestibility, fecal microbial shedding (lower E. coli and higher lactobacillus), and decrease the fecal noxious gas emission in growing pigs when compared with the group fed the basal diet. In conclusion, dietary FC could be considered as a good source of supplementation in growing pigs because of its growth promoting effect. (Key Words: Fermented chlorella, Growing Pig)
\end{abstract}

\section{INTRODUCTION}

Chlorella vulgaris (C. vulgaris) is a genus of unicellular green algae containing high level of protein (50 to $70 \%$ of dry matter), lipid, vitamins and minerals (Phang, 1992). Rania and Hala (2008) had previously suggested that $C$. vulgaris have a higher antimicrobial activity due to the presence of cyclic peptides, alkaloids, and lipopolysaccharides in vitro. Janczyk et al. (2009) also suggested that the inclusion of $C$. vulgaris could benefit the intestinal lactobacillus diversity in laying hens because of the unknown compounds such as polysaccharides, phenolic substances and aromatic compound (Halama, 1990). Therefore, C. vulgaris appears to have the highest potential as a function protein source for the livestock.

\footnotetext{
* Corresponding Author: I. H. Kim. Tel: +82-41-550-3652, Fax: +82-41-565-2949, E-mail: inhokim@ dankook.ac.kr

${ }^{1}$ Ace M\&F Ltd., Seoul, South Korea.

Submitted Jun. 22, 2012; Accepted Aug. 7, 2012; Revised Aug. 28, 2012
}

Buckenhüskes et al. (1990) suggested that a fermentation step could give several advantages (improved flavor, enrichment with desirable metabolites produced by the microorganisms, and enhanced safety) to the vegetable and crops. Our previous studies also confirmed that fermentation process could improve the quality of the soybean meal, fish meal and garlic powder, and subsequently improve the growth performance of the animal (Cho and Kim., 2011; Yan et al., 2011a; Yan et al., $2012 a, b)$. Therefore, it is suitable to hypothesize that fermentation process could also benefit the chlorella utilization in livestock. Indeed, Keijiro (2011) suggested that the inclusion of fermented $C$. vulgaris significantly improved the protein digestibility compared with nonfermented chlorella in rat. Zheng et al. (2012) also demonstrated that dietary fermented $C$. vulgaris could improve the production performance of the laying hens.

However, there is no study concerning the effect of fermented $C$. vulgaris supplementation in pigs. So, the 
objective of the current study is to determine the effect of fermented $C$. vulgaris supplementation on growth performance, nutrient digestibility, blood characteristics, fecal microbial concentration and fecal noxious gas content in growing pigs.

\section{MATERIALS AND METHODS}

The experimental protocols were approved by the Animal Care and Use Committee of Dankook University.

\section{Preparation of fermented $C$. vulgaris}

A commercial product, $C$. vulgaris microalgae produced by fermentation $\left(\mathrm{CBT}^{\circledR}\right)$ was obtained from Celltech, Co. Ltd, Korea. C. vulgaris was inoculated with baker's yeast and lactic acid bacterium. After $72 \mathrm{~h}$ of dry fermentation with cereal broth, fermented $C$. vulgaris then dried at low temperature and ground into powder (Zhang et al., 2012).

\section{Experimental design, animals, and housing}

A total of 96 growing pigs ((Landrace $\times$ Yorkshire $) \times$ Duroc, BW $=26.58 \pm 1.41 \mathrm{~kg}$ ) were randomly allotted into 4 dietary treatments with 6 replicate pens $(2$ barrows and 2 gilts per pen) in a complete block design model. Dietary treatments were: i) negative control (NC), basal diet (without antibiotics); ii) positive control (PC), $\mathrm{NC}+0.05 \%$ tylosin; iii) (fermented chlorella 01) FC01, NC+0.1\% FC, and iv) fermented chlorella 02 (FC02), $\mathrm{NC}+0.2 \%$ FC. Diets (Table 1) were formulated to meet or exceed the nutrient requirements recommended by NRC (1998). Pigs were housed in an environmentally controlled, slatted-floor facility in 36 adjacent pens $(1.8 \times 1.8 \mathrm{~m})$ at the pig farm of Dankook University. All pigs were provided with ad libitum access to feed and water through a self-feeder and nipple drinker, respectively, throughout the experiment. The target room temperature and humidity were $25^{\circ} \mathrm{C}$ and $60 \%$, respectively.

\section{Sampling and measurements}

Pig weights were measured at the beginning and the end of the experiment period, feed consumption were also recorded on a pen basis during the experiment to calculate average daily gain (ADG), average daily feed intake (ADFI), and gain:feed ratio (G:F). Chromium oxide was added to the diet as an indigestible marker at $0.20 \%$ of the diet for $7 \mathrm{~d}$ prior to fecal collection at the 6 th $\mathrm{wk}$ for calculation of DM, N, and energy digestibility. Fecal grab samples were collected at random from at least 2 pigs in each pen ( 1 gilt and 1 barrow). All feed and feces samples were stored immediately at $-20^{\circ} \mathrm{C}$ until analysis. All the feed and fecal samples were freeze-dried and finely ground to be able to pass through a 1-mm screen. The determination of DM (method 934.01), N (method 955.04),
Table 1. Composition of the basal experimental diets (as-fed basis $)^{3}$

\begin{tabular}{|c|c|}
\hline$\overline{\text { Items }}$ & Content \\
\hline \multicolumn{2}{|l|}{ Ingredients $(\mathrm{g} / \mathrm{kg})$} \\
\hline Corn & 553.8 \\
\hline Soybean meal & 334.3 \\
\hline Molasses & 25.0 \\
\hline Animal fat & 53.3 \\
\hline Difluorinated phosphate & 19.3 \\
\hline Limestone & 7.8 \\
\hline L-lysine $\mathrm{HCl}$ & 1.7 \\
\hline Trace mineral premix ${ }^{1}$ & 1.0 \\
\hline Vitamin premix ${ }^{2}$ & 1.2 \\
\hline Salt & 2.0 \\
\hline DL-methionine & 0.3 \\
\hline Choline chloride & 0.3 \\
\hline \multicolumn{2}{|l|}{ Chemical composition } \\
\hline $\mathrm{ME}(\mathrm{kcal} / \mathrm{kg})$ & 3,360 \\
\hline Crude protein $(\%)$ & 20.00 \\
\hline Lysine (\%) & 1.30 \\
\hline Calcium (\%) & 0.90 \\
\hline Phosphorus (\%) & 0.80 \\
\hline \multicolumn{2}{|l|}{ Analyzed composition } \\
\hline GE (kcal/kg) & 4,112 \\
\hline Crude protein $(\%)$ & 19.65 \\
\hline Calcium (\%) & 0.87 \\
\hline Phosphorus (\%) & 0.76 \\
\hline \multicolumn{2}{|c|}{$\begin{array}{l}{ }^{1} \text { Provided per kg of complete diet: } 12.5 \mathrm{mg} \mathrm{Mn}, 179 \mathrm{mg} \mathrm{Zn}, 140 \mathrm{mg} \mathrm{Cu} \text {, } \\
0.5 \mathrm{mg} \text { I and } 0.4 \mathrm{mg} \text { Se. } \\
{ }^{2} \text { Provided per kg of complete diet: } 20,000 \mathrm{IU} \text { of vitamin } \mathrm{A} ; 4,000 \mathrm{IU} \text { of } \\
\text { vitamin } \mathrm{D}_{3} ; 80 \mathrm{IU} \text { of vitamin } \mathrm{E} ; 16 \mathrm{mg} \text { of vitamin } \mathrm{K}_{3} ; 4 \mathrm{mg} \text { of thiamine, } \\
20 \mathrm{mg} \text { of riboflavin; } 6 \mathrm{mg} \text { of pyridoxine; } 0.08 \mathrm{mg} \text { of vitamin } \mathrm{B}_{12} ; 120 \mathrm{mg} \\
\text { of niacin; } 50 \mathrm{mg} \text { of Ca-pantothenate; } 2 \mathrm{mg} \text { of folic acid and } 0.08 \mathrm{mg} \text { of } \\
\text { biotin. } \\
{ }^{3} \text { The additive was included in the diets by replacing the same amount of } \\
\text { corn. }\end{array}$} \\
\hline
\end{tabular}

and energy digestibility were conducted in accordance with the methods established by the AOAC (2000). Chromium levels were determined via UV absorption spectrophotometry (UV-1201, Shimadzu, Kyoto, Japan) and the apparent total tract digestibility (ATTD) of DM, N, and energy were calculated using indirect methods described by Williams et al. (1962).

Two pigs were randomly selected from each pen (1 gilt and 1 barrow) and bled via jugular venipuncture at the beginning of the experiment $(0 \mathrm{~d})$. The same pigs were bled at the end $(35 \mathrm{~d})$ of the experiment. Blood samples were collected into vacuum tubes containing $\mathrm{K}_{3}$ EDTA (Becton Dickinson Vacutainer Systems, Franklin Lakes, NJ, USA) to obtain whole blood. The red blood cells (RBC), white blood cells (WBC) and lymphocyte counts of whole blood samples were determined using an automatic blood analyzer (ADVIA 120, Bayer, Tarrytown, NY, USA).

On 21 and $35 \mathrm{~d}$, fecal samples were collected from 2 
Table 2. Effect of fermented chlorella supplementation on growth performance in growing pigs ${ }^{1}$

\begin{tabular}{lcccccc}
\hline Items & $\mathrm{NC}$ & $\mathrm{PC}$ & $\mathrm{FC01}$ & $\mathrm{FC02}$ & $\mathrm{SE}^{2}$ & $\mathrm{p}$-value \\
\hline Body weight (kg) & & & & & & \\
$\quad$ Initial & 26.63 & 26.57 & 26.53 & 26.57 & 1.41 & 0.215 \\
$\quad$ Final & 52.84 & 54.37 & 54.04 & 53.28 & 1.57 & 0.183 \\
Growth performance & & & & & & \\
ADG (g) & $624^{\mathrm{b}}$ & $662^{\mathrm{a}}$ & $655^{\mathrm{a}}$ & $636^{\mathrm{ab}}$ & 12 & 0.013 \\
ADFI (g) & 1,472 & 1,495 & 1,479 & 1,525 & 43 & 0.236 \\
G/F & 0.424 & 0.443 & 0.443 & 0.417 & 0.013 & 0.118 \\
\hline
\end{tabular}

${ }^{1} \mathrm{NC}=$ Basal diet $; \mathrm{PC}=\mathrm{NC}+$ antibiotics $; \mathrm{FC} 01=\mathrm{NC}+0.1 \%$ fermented chlorella $; \mathrm{FC} 02=\mathrm{NC}+0.2 \%$ fermented chlorella.${ }^{2}$ Standard error

${ }^{\mathrm{a}, \mathrm{b}}$ Means in the same row with different superscripts differ $(\mathrm{p}<0.05)$.

pigs (1 gilt and 1 barrow) randomly selected from each pen by massaging the rectum, after which they were pooled on a pen basis and placed on ice for transportation to the laboratory, where analysis was immediately carried out. $1 \mathrm{~g}$ of fresh sample from each pen was then diluted with $9 \mathrm{ml}$ of $0.1 \%$ peptone broth (Becton, Dickinson and Co.) and homogenized. Viable counts of bacteria in the fecal samples were then conducted by plating serial 10 -fold dilutions (in $1 \%$ peptone solution) onto MacConkey agar plates (Difco Laboratories, Detroit, MI, USA) and lactobacilli medium III agar plates (Medium 638, DSMZ, Braunschweig, Germany) to isolate the E. coli and Lactobacillus, respectively. The lactobacilli medium III agar plates were then incubated for $48 \mathrm{~h}$ at $39^{\circ} \mathrm{C}$ under anaerobic conditions. The MacConkey agar plates were incubated for $24 \mathrm{~h}$ at $37^{\circ} \mathrm{C}$. The E. coli and Lactobacillus colonies were counted immediately after removal from the incubator.

For the analysis of the fecal $\mathrm{NH}_{3}$ and $\mathrm{H}_{2} \mathrm{~S}$, fresh feces were collected from 2 pigs in each pen on the last $2 \mathrm{~d}$ of the experiment. The total sampled feces was then thawed and homogenized, after which the stock feces were stored in 2.6-L plastic boxes with a small hole in the middle of one side that was sealed with adhesive plaster. The samples were allowed to ferment for $1 \mathrm{~d}$ at room temperature $\left(25^{\circ} \mathrm{C}\right)$, after which $100 \mathrm{ml}$ of the headspace air was sampled from approximately $2.0 \mathrm{~cm}$ above the fecal sample. Concentration of $\mathrm{NH}_{3}$ and $\mathrm{H}_{2} \mathrm{~S}$ were measured within the scope of 5.0 to $100.0 \mathrm{ppm}$ (No. 3La, detector tube; Gastec Corp. Kanagawa, Japan) and 2.0 to $20.0 \mathrm{ppm}$ (4LK, detector tube; Gastec Corp.). After collection, box was resealed with adhesive plaster to measure the fecal noxious content at $\mathrm{d} 3$ and 5 as aforementioned. Prior to measurement, the fecal samples were manually shaken for approximately $30 \mathrm{~s}$ to disrupt any crust formation on the surface of the fecal sample and to homogenize the samples. Data of the fecal noxious gas content were presented as the mean value.

\section{Statistical analyses}

Before conducting statistical analysis of the microbial counts, the value was transformed logarithmically. All data were subjected to statistical analysis in a randomized complete block design using the GLM procedures (SAS Inst. Inc., Cary, NC, USA), with the pen serving as the experimental unit. The initial $\mathrm{BW}$ was used as a covariate for the ADFI and ADG, and the initial values were used as a covariate for the blood profile. Duncan's multiple range test was used to compare the means of the treatments. Variability in the data was expressed as the pooled standard error (SE) and a $\mathrm{p}<0.05$ was considered to be statistically significant.

\section{RESULTS}

\section{Growth performance}

The inclusion of PC and FC01 treatment led to a higher $(\mathrm{p}<0.05)$ ADG than those fed NC group (Table 2). No difference ( $p>0.05)$ was observed on the body weight, ADFI and $\mathrm{G}: \mathrm{F}$ ratio during the whole experiment.

\section{Nutrient digestibility and blood characteristics}

No difference $(p>0.05)$ was observed on the apparent total tract digestibility of $\mathrm{N}$ and energy at the end of the experiment (Table 3). Pig fed the PC and FC01 treatment led to a higher $(\mathrm{p}<0.05)$ DM digestibility compared with $\mathrm{NC}$ group, whereas the inclusion of $\mathrm{FC} 02$ treatment did not

Table 3. Effect of fermented chlorella supplementation on nutrient digestibility in growing pigs ${ }^{1}$

\begin{tabular}{lcccccc}
\hline Items (\%) & NC & PC & FC01 & FC02 & SE $^{2}$ & p-value \\
\hline Dry matter & $76.04^{\mathrm{b}}$ & $79.03^{\mathrm{a}}$ & $78.61^{\mathrm{a}}$ & $77.92^{\mathrm{ab}}$ & 1.25 & 0.021 \\
Nitrogen & 78.87 & 79.30 & 78.37 & 78.55 & 1.97 & 0.238 \\
Energy & 75.74 & 78.22 & 76.94 & 76.50 & 1.45 & 0.143 \\
\hline
\end{tabular}

\footnotetext{
${ }^{1} \mathrm{NC}=$ Basal diet PC $=$ NC+antibiotics; FC01 = NC+0.1\% fermented chlorella $; \mathrm{FC} 02=\mathrm{NC}+0.2 \%$ fermented chlorella ${ }^{2}$ Standard error.
}

${ }^{\mathrm{a}, \mathrm{b}}$ Means in the same row with different superscripts differ $(\mathrm{p}<0.05)$. 
Table 4. Effect of fermented chlorella supplementation on blood profiles in growing pigs ${ }^{1}$

\begin{tabular}{lcccccc}
\hline Items & NC & PC & FC01 & FC02 & SE $^{2}$ & p-value \\
\hline RBC $\left(10^{6} / \mu \mathrm{l}\right)$ & 7.77 & 7.61 & 7.59 & 7.70 & 0.31 & 0.152 \\
WBC $\left(10^{3} / \mu \mathrm{l}\right)$ & 19.3 & 19.5 & 19.3 & 19.3 & 0.30 & 0.315 \\
Lymphocyte $(\%)$ & 47.5 & 47.7 & 49.5 & 50.2 & 4.87 & 0.169 \\
\hline
\end{tabular}

${ }^{1} \mathrm{NC}=$ Basal diet; $\mathrm{PC}=$ NC+antibiotics; $\mathrm{FC} 01=\mathrm{NC}+0.1 \%$ fermented chlorella $; \mathrm{FC} 02=\mathrm{NC}+0.2 \%$ fermented chlorella. ${ }^{2}$ Standard error.

Table 5. Effect of fermented chlorella supplementation on fecal microbial in growing pigs ${ }^{1}$

\begin{tabular}{lllllll}
\hline Items $\left(\log _{10} \mathrm{cfu} / \mathrm{g}\right)$ & $\mathrm{NC}$ & PC & FC01 & FC02 & SE $^{2}$ & p-value \\
\hline E. coli & $6.79^{\mathrm{a}}$ & $6.40^{\mathrm{b}}$ & $6.31^{\mathrm{b}}$ & $6.21^{\mathrm{b}}$ & 0.19 & 0.021 \\
Lactobacillus & $7.51^{\mathrm{a}}$ & $7.43^{\mathrm{a}}$ & $7.78^{\mathrm{b}}$ & $7.96^{\mathrm{b}}$ & 0.16 & 0.016 \\
\hline
\end{tabular}

${ }^{1} \mathrm{NC}=$ Basal diet; $\mathrm{PC}=\mathrm{NC}+$ antibiotics $; \mathrm{FC} 01=\mathrm{NC}+0.1 \%$ fermented chlorella $; \mathrm{FC} 02=\mathrm{NC}+0.2 \%$ fermented chlorella.${ }^{2}$ Standard error.

${ }^{\mathrm{a}, \mathrm{b}}$ Means in the same row with different superscripts differ $(\mathrm{p}<0.05)$.

( $>0.05)$ increase the DM at the end of the experiment. Moreover, blood characteristics were not affected $(\mathrm{p}<0.05)$ by the treatment throughout the experiment (Table 4).

\section{Fecal microbial shedding and fecal noxious gas content}

The inclusion of PC treatment reduced the fecal E. coli $(\mathrm{p}<0.05)$ compared with NC treatment (Table 5), whereas the lactobacillus were not affected. Dietary FC supplementation led to a significant $(\mathrm{p}<0.05)$ higher lactobacillus concentration and lower $E$. coli concentration than the NC treatment. Moreover, pig fed FC or PC treatment reduced $(\mathrm{p}<0.05)$ the fecal $\mathrm{NH}_{3}$ and $\mathrm{H}_{2} \mathrm{~S}$ content compared with those fed NC treatment (Table 6).

\section{DISCUSSION}

\section{Effect of antibiotics supplementation}

It is evident from the current study that pig fed antibiotic supplemented diet led to a higher ADG than those fed the NC treatment. In agreement with our study, Yan et al. (2012c) also reported an increased growth performance with antibiotics supplementation, and suggested that the reason for the improved growth performance is likely to be the increased nutrient digestibility. Similar in our study, an increased DM digestibility was also observed with the antibiotic supplementation. It is well accepted that dietary antibiotic supplementation could decrease the pathogenic bacteria in the intestine, and subsequently increased the nutrient digestibility of pigs. Nagy and Fekete (1999) also suggested that $E$. coli in the intestine may decrease the nutrient digestibility and growth performance in farm animals. In this study, the inclusion of antibiotic significantly reduced the $E$. coli concentration compared with basal diet, which reflected the increased nutrient digestibility and confirmed the beneficial effect of antibiotics supplementation in growing pigs.

\section{Effect of FC supplementation}

In the current study, a marginally positive effect on the ADG was observed with the FC supplementation at the level of $1 \%$ compared with NC group. It has been suggested that the Chlorella contained growth promoting substance such as S-nucleotide adenosyl peptide complex, which may affect the growth performance and digestibility of the animals (Han et al., 2002). Halama (1990) also suggested there are many kind of unknown compounds such as polysaccharides, phenolic substances and aromatic compound in the algae, which are nutritional and ecological important to the animals. Therefore, it is suitable to hypothesize that the inclusion of Chlorella could improve the growth performance of the pigs. Moreover, some recent studies also confirmed that FC supplementation improved production performance in laying hens (Zheng et al., 2012). Obviously, our results indicated that pig fed FC01 treatment led to a higher ADG than those fed NC treatment, which confirmed the beneficial effect of the FC in pigs. Besides, the inclusion of FC01 led to a higher DM digestibility than the NC treatment, which is in agreement with Keijiro (2011), who suggested that rat fed fermented C. vulgaris supplemented diet led to a higher nutrient digestibility than those fed non-fermented chlorella. Furthermore, Hasegawa et al. (2000) had previously suggested that C. Vulgaris could protect the mice from the immune-suppressive action of stress and following gastric ulcer formation. Justo et al.

Table 6. Effect of fermented chlorella supplementation on fecal noxious gas content in growing pigs ${ }^{1}$

\begin{tabular}{lcccccc}
\hline Items $(\%)$ & $\mathrm{NC}$ & PC & FC01 & FC02 & SE $^{2}$ & p-value \\
\hline $\mathrm{NH}_{3}$ & $5.91^{\mathrm{a}}$ & $3.89^{\mathrm{b}}$ & $4.21^{\mathrm{b}}$ & $3.76^{\mathrm{b}}$ & 0.81 & 0.015 \\
$\mathrm{H}_{2} \mathrm{~S}$ & $7.94^{\mathrm{a}}$ & $5.25^{\mathrm{b}}$ & $5.40^{\mathrm{b}}$ & $5.01^{\mathrm{b}}$ & 1.21 & 0.007 \\
\hline
\end{tabular}

${ }^{1} \mathrm{NC}=$ Basal diet $; \mathrm{PC}=\mathrm{NC}+$ antibiotics; FC01 $=\mathrm{NC}+0.1 \%$ fermented chlorella $; \mathrm{FC} 02=\mathrm{NC}+0.2 \%$ fermented chlorella.${ }^{2}$ Standard error.

${ }^{a, b}$ Means in the same row with different superscripts differ $(\mathrm{p}<0.05)$. 
(2001) also demonstrated the immune modulating and anticancer properties of the microalgae $C$. Vulgaris in mice. Therefore, the improved immune statues could also explain the beneficial effect observed on the growth performance and nutrient digestibility in the current study. However, to the best of knowledge, this is first study concerning the effect of FC supplementation in pig, no study could be compared with the current study. Further study is still necessary to investigate the effect and mechanism how the FC affect the animal before putting the FC into practice utilization.

It is well accepted that gastrointestinal microflora play an important roles in animal production because intestine is the largest nutrient adsorption part in pigs; our previous study in pigs also concluded that fecal microbial is highly associated with the production performance of the pigs (Yan et al., 2012c). Therefore, fecal microbial shedding was investigated to evaluate the FC supplementation in pigs. In the current study, our results indicated that pigs fed FC supplemented diet led to a lower $E$. coli concentration but higher lactobacillus concentration than those fed NC group. Lin (1969) had previously suggested that the inclusion of Chlorella growth factor could increase the lactobacillus concentration by up to $400 \%$ in vitro, and confirmed the beneficial effect of $C$. Vulgaris on the lactobacilli diversity in vivo (Janczyk et al., 2009). Rania and Hala (2008) also suggested that the extract of Chlorella had antibacterial activities against $E$. coil because of the present of alkaloids and lipopolysaccharides. Therefore, we hypothesized that the FC supplementation might increase the gut health and subsequently explain the apparent total tract digestibility and growth performance in this study.

In terms of the fecal noxious gas content, the inclusion of FC significantly decreased the fecal noxious gas content compared with NC group. Ferket et al. (2002) have previously suggested that the ultimately fecal noxious gas emission of animals is related to intestinal microflora, especially the harmful intestinal bacteria population. Our previous study also suggested that a lower fecal noxious gas content could be observed in pigs by manipulating the microflora in the gastrointestinal tract of pigs (Yan et al., 2012c). Besides, several studies also suggested that the fecal noxious gas content is related to the nutrient digestibility (Yan et al., 2010b; Yan et al., 2011b), because the increased digestibility may allow less substrate for the microbial fermentation in the large intestine, which consequently decrease the fecal noxious gas content. In our study, pig fed the FC supplemented diet led to a better balanced microflora in the intestine and higher nutrient digestibility than those fed the NC group. Therefore, we hypothesized that the reason for the reduction in fecal noxious gas content may be the results of increased nutrient digestibility and the benefited microflora in the gastrointestinal tract of pigs.

\section{CONCLUSION}

In conclusion, our results indicated that the inclusion of fermented chlorella at the level of $0.1 \%$ could improve the growth performance, nutrient digestibility, fecal microbial shedding (lower E. coli and higher lactobacillus), and decrease the fecal noxious gas emission an in growing pigs when compared with the NC group. Dietary FC could be considered as a good source in growing pig because of its growth promoting effect.

\section{REFERENCES}

AOAC. 1995. Official methods of analysis. 16th ed. Assoc. Off. Anal. Chem. Washington, DC, USA.

Buckenhüskes, H., H. A. Jensen, R. Andersson, A. G. Fernandez and M. Rodrigo. 1990. Fermented vegetables. In: Processing and Quality of Foods in Food Biotechnology (Ed. P. Zeuthen, J. C. Cheftel, C. Eriksson, T. R. Gormley, P. Linko and K. Paulus): Avenues to Healthy and Nutritious Products . Elsevier, London.

Cho, J. H. and I. H. Kim. 2011. Effects of fermented fish meal on $\mathrm{N}$ balance and apparent total tract and ileal amino acid digestibility in weaning pigs. J. Anim. Vet. Adv. 10:1455-1459.

Ferket, P. R., E. van Heugten, T. A. T. G. van Kempen and R. Angel. 2002. Nutritional strategies to reduce environmental emissions from nonruminants. J. Anim. Sci. 80(E. Suppl. 2), E168-E182.

Halama, D. 1990. Single cell protein. In: Nonconventional Feedstuffs in the Nutrition of Farm Animals (Ed. K. Boda). Elsevier Science Publishing Company, Inc. 655 Avenue of Americas, New York, N.Y. 10010. pp. 34-49.

Han, J. G., G. G. Kang, J. K. Kim and S. H. Kim. 2002. The present status and future of Chlorella. Food Sci. Ind. 6:64-69.

Hasegawa, T., K. Noda, S. Kumamoto, Y. Ando, A. Yamada and Y. Yoshikai. 2000. Chlorella vulgaris culture supernatant (CVS) reduces psychological stressinduced apoptosis in thymocytes of mice. Int. J. Immunopharmacol. 22:877-885

Janczyk, P., B. Halle and B. Souffrant. 2009. Microbial community composition of the crop and ceca contents of laying hens fed diets supplemented with Chlorella vulgaris. Poult. Sci. 88:2324-2332.

Justo, G. Z., M. R. Silva and M. L. S. Queiroz. 2001. Effects of the green algae Chlorella vulgaris on the response of the host hematopoietic system to intraperitoneal Ehrlich ascites tumor transplantation in mice. Immunopharmacol. Immunotoxicol. 23:119-132.

Keijiro, U. 2011. Method for producing Chlorella fermented food. United States Patent. Patent No.: US 7,914,832 B2

Lin, Y. C. 1969. The supplementary effect of algae on the nutritive value of soybean milk. J. Formos. Med. Assoc. 68:15-21.

Nagy, B. and P. Z. Fekete. 1999. Enterotoxigenic Escherichia coli (ETEC) in farm animals. Vet. Res. 30:259-284.

NRC. 1998. Nutrient requirements of swine. 9th rev, ed. Natl. Acad. Press, Washington, DC, USA.

Phang, S. M. 1992. Role of algae in livestock-fish integrated 
farming system. Proceedings of the FAO/IPT Workshop on Integrated Livestock-Fish Production System (Ed. T. K. Mukherjee, P. S. Moi, J. M. Panandam and Y. S. Yang); 16-20 Dec., 1991, University of Malaya, Kuala Lumpur, Malaysia. 49-56.

Rania, M. A. and M. T. Hala. 2008. Antibacterial and antifungal activity of cyanobacteria and green microalgae. Evaluation of medium components by placket-burman design for antimicrobial activity of Spirulina platensis. Global J. Biotechnol. Biochem. 3:22-31.

Williams, C. H., D. J. David and O. Iismaa. 1962. The determination of chromic oxide in faeces samples by atomic absorption spectrophotometry. J. Agric. Sci. 59:381-385.

Yan, L., Q. W. Meng, X. Ao, T. X. Zhou, J. S. Yoo, H. J. Kim and I. H. Kim. 2011a. Effects of fermented garlic powder supplementation on growth performance, blood characteristics and meat quality in finishing pigs pigs fed low-nutrient-density diets. Livest. Sci. 137: 255-259

Yan, L., J. P. Wang, H. J. Kim, Q. W. Meng, X. Ao, S. M. Hong and I. H. Kim. 2010b. Influence of essential oil supplementation and diets with different nutrient densities on growth performance, nutrient digestibility, blood characteristics, meat quality and fecal noxious gas content in grower-finisher pigs. Livest. Sci. 128:115-122.
Yan, L., Q. W. Meng and I. H. Kim. 2011b. The effect of an herb extract mixture on growth performance, nutrient digestibility, blood characteristics and fecal noxious gas content in growing pigs. Livest. Sci. 141:143-147.

Yan, L., J. P. Wang and I. H. Kim. 2012a. Effects of different fermented soy protein and apparent ileal digestible lysine levels on weaning pigs fed fermented soy protein amended diets. Anim. Sci. J. 83:403-410.

Yan, L., Q. W. Meng and I. H. Kim. 2012b. Effects of fermented garlic powder supplementation on growth performance, nutrient digestibility, blood characteristics, and meat quality in growing-finishing pigs. Anim. Sci. J. 83:411-417

Yan, L., Q. W. Meng and I. H. Kim. 2012c. Effect of an herb extract mixture on growth performance, nutrient digestibility, blood characteristic, and fecal microbial shedding in weaning pigs. Livest. Sci. 145:189-195

Zheng, L. S. T. Oh, J. Y. Jeon, B. H. Moon, H. S. Kwon, S. U. Lim, B. K. An and C. W. Kang. 2012. The dietary effects of fermented Chlorella vulgaris (CBT) on production performance, liver lipids and intestinal microflora in laying hens. Asian-Aust. J. Anim. Sci. 25:261-266. 